nancy have already begun to be appreciated. These studies add another dimension, carcinogenesis. The administration of stilboestrol to the mother in early pregnancy must now be considered as a probable cause of adenocarcinoma developing in their daughters. The onus on investigators is to refute this contention rather than confirm it, and the story should encourage even greater caution before administering any drug to a pregnant woman.

J. Folkman ${ }^{5}$ has raised another issue-namely, the possible effects of stilboestrol residue in meat. Apparently since $195475 \%$ of cattle in America have been fed on stilboestrol to increase their weight. Sweden and other countries have already banned the feeding of this hormone to cattle. ${ }^{8}$ In Britain it has been used on a small scale for some time to fatten veal and some poultry and had been passed as safe under the Voluntary Veterinary Products Safety Protection Scheme. This body was last week superseded by a Veterinary Products Committee set up under the Medicines Commission, and it is to be hoped the new body will examine the facts afresh. Stilboestrol is used for fattening animals in the veal and poultry trade, being injected in a slow-release preparation under the ear of calves and into the back of the head of chickens. These sites have been chosen because they would not enter into human food. But the extent to which stilboestrol may enter it, and the possible consequences, ought to be looked at again.

Herbst, A. L., and Scully, R. E., Cancer, 1970, 25, 745.
Herbst, A. L., Ulfeloer, H., and Poskanzer, D. C., New England fournal of Medicine, 1971, 284, 878 .

3 Greenwald, P., Barlow, J. J., Nasca, P. C., and Burnett, W. S., New England Fournal of Medicine, 1971, 285, 390.

Smith, A. W., American fournal of Obstetrics and Gynecology, 1948, 56, 821. s Folkman, J., New England fournal of Medicine, 1971, 285, 404.

Willis, R. A., Pathology of Tumours, 4th edn., p. 560. London, Butterworth, 1967.

7 Meissner, W. A., Sommers, S. C., and Sherman, G., Cancer, 1957, 10,

8 Epstein, S., cited by Greenwald et al. ${ }^{3}$

\section{Pathogenesis of Diabetes Mellitus}

Two recent symposia have considered the pathogenesis of diabetes. ${ }^{1} 2$ Curiously, in neither was there any serious discussion of exactly what diabetes is, which in the light of modern knowledge is rather like Hamlet without the Prince of Denmark.

One of the old hypotheses, that diabetes is due to persistent antagonism to insulin, now seems to be untenable. The subject was reviewed by D. M. Kipnis, ${ }^{3}$ who pointed out that the several studies of insulin secretion in patients with an increased statistical risk of developing diabetes (potential diabetics in Britain; prediabetics in the U.S.A.) all showed that the secretion of insulin in them was normal or slightly depressed. Only in obese people is the biological effectiveness of insulin reduced. 45 That an impaired mechanism for the release of insulin is the basic defect in diabetes is now widely canvassed, particularly by $\mathbf{E}$. Cerasi and $R$. Luft. ${ }^{6}$ These investigations have used as their tool a glucose infusion test, measuring levels of blood glucose and plasma insulin. They have laid special emphasis on the initial insulin response and have found it to be impaired in potential diabetics-in this case the healthy members of monozygotic twin pairs of which the other member has diabetes. This abnormality of insulin release was ac- companied by a glucose tolerance response within the normal range. In other people with impaired glucose tolerance or with overt diabetes the initial peak of the insulin response was reduced or missing. This type of abnormality was also seen in $15-20 \%$ of unselected healthy adults and in a similar proportion of children. Cerasi and Luft suggest that people showing this type of insulin response have inherited a predisposition to diabetes, while the actual appearance of the disease is being determined by other factors. Though the findings are similar in other studies of potential diabetics investigated by different methods, the evidence remains circumstantial, and follow-up studies are required on patients with and without the abnormal insulin response to test the hypothesis. It is of course possible to stand the argument on its head by suggesting that the abnormal insulin response in the twin of a diabetic may actually be protecting that person against diabetes, or is linked with some protective mechanism.

A hypothesis at present arousing some controversy is one put forward by $M$. D. Siperstein and his colleagues. ${ }^{7}$ They have measured the thickness of the capillary basement membrane in muscle biopsies taken from diabetics, from normal persons, and from a group of potential diabetics (offspring of two diabetic parents). Siperstein found that the mean thickness of the muscle capillary basement membrane in the diabetics and potential diabetics was greater than in the controls. Thus, $8 \%$ of the normals, $99 \%$ of the diabetics, and $53 \%$ of the potential diabetics exceeded an arbitrary upper limit of normal. He failed to find any thickening of the membrane in patients with secondary diabetes and concluded that hyperglycaemia is not the cause of that thickening of the basement membrane. Rather, he considers, the microangiopathy probably precedes the hyperglycaemia of diabetes and may even cause it. This view receives some slight support from a recent paper by $H$. P. Katz and colleagues. ${ }^{8}$ They observed in young children with diabetes of relatively short duration an increase in the pulse wave velocity, which is influenced by a number of factors, including arterial wall elasticity. ${ }^{9}$ If true, this hypothesis has important implications; hence its controversial nature. Conventional therapy is directed at hyperglycaemia and if this is unrelated to angiopathy the whole basis of treatment will require rethinking. J. R. Williamson ${ }^{10}$ has strongly challenged Siperstein's thesis, however. While using similar techniques, he has been unable to produce Siperstein's results, and it is not clear whether the discrepancies are due to methodological or to sampling differences. It is to be hoped that more data will clarify the issue.

The inescapable conclusion from these discussions is that no single cause can be postulated for all cases of diabetes. This point is emphasized in a contribution by $\mathrm{J}$. $\mathbf{H}$. Edwards ${ }^{11}$ on the genetic aspects of diabetes. He points out that despite extensive study the inheritance of diabetes (like that of other common disorders) remains controversial. Whatever the nature of the mode of inheritance, it seems that environmental factors determine most cases of diabetes, and, as $R$. Levine states," "we should study more the evocative factors which produce overt diabetes, because there is some hope of preventing them."

\footnotetext{
1 Pathogenesis of Diabetes Mellitus, Nobel Symposium 13, ed. E. Cerasi and

R. Luft. Stockholm, Almquist and Wiksell, 1970. Luft and P. J. Randle. Milano, Casa Editrice "Il Ponte," 1971.

- Kipnis, D. M., in Pathogenesis of Diabetes Mellitus, ed. E. Cerasi and R. Luft, p. 45.

- Perley, M., and Kipnis, D. M., Fournal of Clinical Investigation, 1967, 46, 1954 .
} 
S Seltzer, H., Allen, E. W., Herron, A., jun., and Brennan, M., fournal of Clinical Investigation, 1967, 46, 323.

- Cerasi, E., and Luft, R., in Pathogenesis of Diabetes Mellitus, ed. E. Cerasi and R. Luft, p. 18 .

' Siperstein, M. D., in Pathogenesis of Diabetes Mellitus, ed. E. Cerasi and

R. Luft, p. 81 .
Katz, H. P., Cheitlin, M. D., Wasser, A. H., and Flair, R. C., fohns Hopkins Medical Fournal, 1970, 127, 337

- Woolam, G. L., Schnur, P. L., Vallbona, C., and Hoff, H. E., Circulation. 1962, 25, 533 .

10 Williamson, J. R., in Blood Vessel Disease in Diabetes Mellitus, 5th Capri Conference, ed. K. Lundbaek and H. Keen. Milano, Casa Editrice "Il Ponte," 1971. In press.

${ }^{11}$ Edwards, J. H., in On the Pathogenesis of Diabetes Mellitus, ed. R. Luft and P. J. Randle, p. 360.

12 Levine, R., in On the Pathogenesis of Diabetes Mellitus, ed. R. Luft and P. J. Randle, p. 377.

\section{Flatulence}

The patient with dizzy turns is the bane of the neurologist, and the equivalent to the gastroenterologist must be the person complaining of flatulence and abdominal distension. Both problems are as common as they are apt to be baffling to investigate. Though patients believe intestinal gas often causes abdominal symptoms, the physician does not always agree. He tends to regard such complaints as functional and to emphasize that the gaseous content of the bowel is influenced chiefly, if not entirely, by the amount swallowed.

A recent study suggests that this view could be mistaken. ${ }^{1}$ Analyses of the volume and composition of intestinal gas were made in 11 normal persons by infusing the inert gas argon at a constant rate through a small intestinal polyvinyl tube and collecting the washout gases at the rectum. Within 15 to 20 minutes of the start of the infusion gas could be collected at the rectum at roughly the same rate as that of the infusion. After an initial washout phase in which the quantities of nitrogen and other gases in the gut at the start of the study were obtained, a steady state of gas output was achieved which could be related to gas production. Calculations based on the first phase showed that total volumes of 30 to $200 \mathrm{ml}$ were present, predominantly as nitrogen, the remainder being mainly hydrogen and carbon dioxide with occasionally some methane. In the steady state the quantity of nitrogen washed out tended to be small and relatively constant, and the main gaseous component was carbon dioxide, with lesser amounts of hydrogen and methane.

The importance of swallowed air as a contributor to the nitrogen content of the bowel cannot be assessed from these experiments, because all such gas was removed by constant gastric suction. The steady-state studies suggest that 1-2 $\mathrm{ml} / \mathrm{min}$ is added by diffusion. The presence of hydrogen and methane are a tribute to bacterial activity. Neither gas can be found in the bowel of germ-free animals ${ }^{2}$ or newborn babies, ${ }^{3}$ and other studies show that hydrogen is normally produced in the colon ${ }^{5}$ unless there is excessive growth of bacteria in the small intestine. ${ }^{6} 7$ Furthermore the addition of a small amount of a sugar such as lactose to the bowel considerably increases gas formation. ${ }^{6}$

Production of gas in the human intestine is insignificant in quantity compared with that of ruminants, and the clinical problems lack the dramatic quality of cattle bloat. Abdominal distention is a common complaint in association with carbohydrate malabsorption, a feature emphasized by the fact that production of hydrogen in the breath has been used as an indirect indication of sugar intolerance. 89 The rate of carbon dioxide output in flatus closely follows that of hydrogen and is also probably in great part a product of fermentation reactions in the large bowel. ${ }^{10}$ Certain foods such as beans have a reputation with the public as gas producers, a reputation confirmed by studies showing a large increase in production of flatus and the concentration of hydrogen in expired air of people consuming the beans. ${ }^{10} 11$ The factor responsible for the gas would seem to be in a component containing nonabsorbed oligosaccharides such as raffinose and stachyose. ${ }^{9}$

The relative importance of swallowed air and of gas generated in the bowel as causes of symptoms have yet to be assessed. In people not complaining of flatulence the swallowed air probably contributes about $60 \%$ at the most to the ouput of flatus as determined by nitrogen content. 1 But whether the flatulent are in general swallowers of air or generators of gas or even specially sensitive to distension remains obscure.

${ }^{1}$ Levitt, M. D., New England fournal of Medicine, 1971, 284, 1394. Levitt, M. D., French, P., and Donaldson, R. M., Fournal of Laboratory

3 Levitt, M. D., Gastroenterology, 1970, 59, 921.

' Richards, E. A., Steggerda, F. R., and Murata, A., Gastroenterology, $1968,55,502$.

L Levitt, M. D., and Ingelfinger, F. J., Annals of the New York Academy of Sciences, 1968, 150, 75.

- Levitt, M. D., New England fournal of Medicine, 1969, 281, 122.

Calloway, D. H., Colasito, D. J., and Mathews, R. D., Nature, 1966, 212, 1238.

Calloway, D. H., and Murphy, E. L., Annals of the New York Academy of Sciences, 1968, 150, 82.

Levitt, M. D., and Donaldson, R. M., fournal of Laboratory and Clinical Medicine, 1970, 75, 937.

Steggerda, F. R., Annals of the New York Academy of Sciences, 1968, $150,57$.

11 Calloway, D. H., Gastroenterology, 1966, 51, 383.

\section{Modified Prefrontal Leucotomy}

Prefrontal leucotomy is a subject on which opinions are divergent and firmly held. The divergence is not surprising in view of the lack of knowledge. It is an astonishing fact that in the 35-year history of leucotomy, during which more than 100,000 patients must have been operated on, no prospective controlled trial has been carried out to compare its effectiveness with non-surgical treatment. There has bien one controlled trial in which different forms of leucotomy have been compared with each other. ${ }^{1}$ The fact that some doctors are enthusiastic about the operation, whereas others refuse to refer their patients as a matter of principle, ${ }^{2}$ is also not surprising in view of the seriousness of the conditions for which the operation is carried out and the irreversible damage it inflicts on what may be the highest centres of the human mind and spirit. In this situation a certain rigid extremity of opinion can be predicted from psychological theory, ${ }^{3}$ and this rigidity is not conducive to the scientific impartiality of judgement which is an essential intellectual background to a good clinical trial.

However, there is general agreement on at least one point. The original standard leucotomy in its various forms, in which the white matter of both frontal lobes is severed in a coronal plane anterior to the lateral ventricles, should not be used. This operation, which was introduced by Egas Moniz in 1936 and won him the Nobel prize in 1949, has been found to have too many undesirable side effects, and in two retrospectively controlled trials the leucotomized patients fared no better than similar unoperated patients. ${ }^{45}$ In a recent ten-year follow-up of 134 men who underwent standard leucotomy 6 nearly half were disabled by seizures and a 